\title{
A Trip down Memory Lane? New Challenges from Other Disciplines
}

I have had the good fortune in my academic career as a computer science lecturer to mix with scholars from several disciplines. As a long-standing member of the Association for History and Computing $(\mathrm{AHC})^{1}$, I have worked with mainstream historians over the last fifteen years. I first met this group when creating a specialised historical database for my $\mathrm{PhD}$ in the history of mathematics. More recently $\mathrm{I}$ have learned from French historians as I completed a French degree which majored in history. With all these groups, I have looked carefully at their historical practice to see if there were any good crumbs dropping off their tables that we could use in the history of computing. However, I remember chatting to an AHC convenor at a conference in Tromso, Norway in 2003 and asking for any help in this area. He answered somewhat witheringly that the history of computing did not need a historiography. I disagreed and have continued looking for good practice and inspiration from other fields to improve our discipline. Here are my thoughts so far as presented to SHOT $2007^{2}$, starting with the history of mathematics.

\section{The History of Mathematics}

The celebrated historian of mathematics, Kenneth O. May ${ }^{3}$, differentiates between chronology and history, emphasizing the need to subject chronological knowledge to the practices of selection, analysis and insight before it can become history. As to pioneer contributions, he advises "I should comment on participants becoming historians. There are pitfalls in this, of course, because people's memories are not precise. But that does not matter. The essence of historical scholarship is to use memoirs and other primary sources with discretion. And so a person who has participated shouldn't worry about the bias that he has because of his own participation. The historians will take care of that in

due time by comparing sources, checking dates and so on". ${ }^{4}$ May's guidelines constitute good historical practice, but the salient issue for historians of computing is whether we are following his demand for objectivity?

\section{Developments in the History of Computing}


Recent contributions to the historiography debate include Tom Misa's Annals article which draws on an essay by Martin Campbell-Kelly. ${ }^{6}$ There are several key points to highlight from these two papers. Campbell-Kelly discusses three communities / ages of history of computing, those of the: 1) 'internalist' accounts: firsts, histories of individual computers; 2) professional historians of computing: working on the history of software engineering, for example, considering bigger themes, within the auspices of history of science and technology; and 3) integrators, not historians of computing as such, but treating the history of computing as part of the Information Age. It might be tempting to look simplistically at these three stages as being strictly consecutive, each one completed before the next is started. In this way, the original works on 'men and machines' would never be revisited. However, Campbell-Kelly argues that 'history has to be re-written for each generation' and he favourably reviews a historian who "uses familiar sources and already well researched histories, but he views them from a late $20^{\text {th }}$ century

perspective." "7 Campbell-Kelly thus endorses the need for re-interpretation / evaluation of previously well-established accounts. Misa suggests a fourth theme whereby the history of computing will become a hybrid field, linked with other branches / methods and "should be situated within and as a vital part of major historical transformations." 8 France is a country that has experienced several such transformations.

\section{French History and Memory}

There are two areas of key interest to highlight from French history: general historical interpretation and memory studies. For the former, a good current example is the analysis of the events of May 1968, very much in the news now on the occasion of the fortieth anniversary of this 'imaginary' revolution'. Over the years, multiple interpretations of these events have been posited, debated, analysed and re-analysed, with seven key interpretations of the May events having gained general acceptance ${ }^{10}$. There were also major re-evaluations undertaken ten and twenty years later, and no doubt this year will bring a new wave of them in this fortieth anniversary year. How much do we go back and re-evaluate in the history of computing? Campbell-Kelly observes: "Twenty years ago, there was a sense of a cumulative enterprise in the history of computing - that what we did was of permanent value. If was as if article written or each book published was something that could be crossed off a giant "to-do list". But what happened was that 
the computer redefined itself. This made the old questions irrelevant, or at least the answers to be of less value." ${ }^{11}$ French historians and historians of computing like Campbell-Kelly do reappraise historical events in the light of new evidence / theory, but it seems there are too many in our field who view the original works of pioneers as sacred, and therefore never to be questioned. Hence accounts of events are seldom challenged, revisited or re-interpreted. Memory studies give us a new window to explore past events.

Pierre Nora's epic three-volume Lieux de Mémoire ${ }^{12}$ and Henri Rousso's Le Syndrome de Vichy ${ }^{13}$ constitute seminal works in this recent field, treating France's reaction to difficulties in her past or present. Nora argues that a prime function of a site of memory is to freeze in time a situation. He emphasizes the need for a strong will to memorialize such sites which keep to the fore collectively-remembered values, thus keeping the past tied to the present. He highlights the partisan nature of memory: "Memory, insofar as it is affective and magical, only accommodates those facts that suit it: it nourishes recollections that may be out of focus or telescopic...Memory is blind to all but the group it binds,... History on the other hand, belongs to everyone and to no one, whence its claim to universal authority." 14 Similarly Rousso states "What is it that groups, elites, nations remember from their past? What do they want to remember, and what do they repress?...To what contemporary uses are memories put? How divisive are these remembrances and concealments...?"15 These two seminal historians thus pinpoint the selective nature of memory studies, showing how it is possible for whole sections of a 'historical' investigation to be systematically ignored. David Anderson has recently delivered a major challenge to the received account of the development of the Manchester Baby in his paper from the Turing conference 2004 proceedings, published on the British Computer Society Electronic Workshops in Computing (BCS eWiC) Website. ${ }^{16}$ Anderson stresses the pivotal role of the engineer Tom Kilburn whose memory, he argues, has been the source of the predominant account which has lasted sixty years and favors the engineers' account whilst eliding the mathematicians' contribution. Memory studies has subsequently provided a framework for Anderson and I to re-appraise the events around the Manchester Baby development, as presented to the British Society for the History of Science in Manchester 2007. In his paper Anderson 
attacks three prevalent myths, and we investigated the commemorations and influence of memory in terms of the engineers and the mathematicians. Our conclusion is that there is a much more complex story than the dominant discourse that the engineers did nearly everything. Anderson provides evidence of government involvement and technology transfer that has previously been ignored, so a re-examination of this topic actually feeds into the wider debate of historical transformations, as advocated by Misa.

\section{Conclusions}

Campbell-Kelly's encouragement to re-evaluate and Misa's exhortation to work with those from other disciplines are timely and helpful. We need to embrace some of the typical historiographical practices of more mature disciplines such as French history and the history of mathematics, and apply them to the historiography of the history of computing. In this way we will enliven the debate, deepen the scholarship and we should find computing indeed in its rightful place within major historical transformations, as Misa advocates. The field of memory studies helps us to recognize typical traits in historical recollections, particularly where they support a strong tradition built up around a pioneer, machine or institution. It is helpful to keep in mind the contrast between these memories kept alive by passing the baton from generation to generation, and the objective nature of historical study. Whatever our approach, there should always be plenty of room for an engaging, stimulating technological and social history as promoted by Nathan Ensmenger. ${ }^{17} 1400$ words

\footnotetext{
${ }^{1}$ There are various branches: see http://www.gla.ac.uk/centres/hca/ahc/ for the UK and http://www.theaahc.org/main.htm for the USA.

${ }^{2}$ Society for the History of Technology Conference 2007 held in Washington

${ }^{3}$ From a posthumous paper Kenneth O. May, "Historiography: A Perspective for Computer Scientists", Academic Press, 1980, pp. 11-18, based on a talk given in 1977.

${ }^{4}$ K.O. May pp.14-15.

5 T. Misa, "Towards an Historical Understanding of 'How Computing has Changed the World'," The Annals of the History of Computing, vol. 29, no. 4, 2007, 52-63.

${ }^{6}$ M. Campbell-Kelly, "The History of the History of Computing", 2002. The essay can be found at http://www.iee.org/OnComms/pn/History/HistoryWk_History_of_Computing.pdf, accessed $2^{\text {nd }}$ May 2008.
} 
${ }^{7}$ M. Campbell-Kelly, p6.

${ }^{8}$ T. Misa, p. 56.

${ }^{9}$ M. Seidman, The Imaginary Revolution, Berghahn Books, 2004.

${ }^{10}$ See for example K.A. Reader, The May 1968 Events in France, St. Martin's Press.

${ }^{11}$ M. Campbell-Kelly, p5.

${ }^{12}$ P. Nora's, Les Lieux de Mémoire, Gallimard, 1984-1992. (the English version is Realms of Memory but Sites or Places would be a better translation).

${ }^{13}$ H. Rousso, Le Syndrome de Vichy : De 1944 à nos jours, Editions du Seuil, 1987, (the Vichy Syndrome, from 1944 to our time).

${ }^{14}$ P. Nora, "Between Memory and History: Les Lieux de Memoire", Representations, no. 26, 1989, p9. (a reprint of the introduction to the first volume)

${ }^{15} \mathrm{H}$. Rousso, pvii.

${ }^{16} \mathrm{http} / / /$ www.bcs.org/server.php?show=ConWebDoc.17134 David Anderson "Was the Manchester Baby conceived at Bletchley Park?"

${ }^{17}$ N. Ensmenger, "Power to the People: Toward a Social History of Computing", Annals of the History of Computing, vol ?, no. ?, 2004, pp. 94-6. 